\title{
Smart school: A comparative research between two Islamic countries, Malaysia and Iran
}

\author{
Sirous Tabrizi ${ }^{1 *}$, Mohammad Kabirnejat ${ }^{2}$ \\ ${ }^{1}$ University of Windsor, Windsor, Canada \\ ${ }^{2}$ Islamic Azad University, Hashtrood Branch, Iran
}

\section{Key Words}

Migrant workers

Remittances

Determinants

Intention to return

Received: 12 July 2016

Accepted: 20 August 2016

Published: 27 February 2017

\begin{abstract}
In this paper, Smart Schools in Malaysia and Iran will be examined and compared to understand what opportunities and barriers still exist for improving the value and access of these schools. A smart school is a learning institution that uses non-traditional means of instruction, teaching, and learning where school management is focused on helping students cope with and leverage changes brought about by, the information age. The smart school program will be examined for both the state-sponsored public sector (state schools) and privately funded sector (private schools). Globalization requires a more practical education system in which outputs can work in complicated situations with modern instruments. Many developing countries prefer to establish an education system with Smart Schools to achieve education quality closer to developed countries. Successful smart schools' requirements are different from traditional schools in curriculum, pedagogy, assessment, teaching-learning material, management, visions, and stakeholder engagement. Malaysia successfully established this system from early 1996, and Iran has tried to also establish a smart school system since 2002.
\end{abstract}

(C2017 The Author(s). published by TAF Publishing.

\section{INTRODUCTION}

Schools have an essential role in preparing students to become productive members of society (Elias, 1997). Educators around the world have the same vision for their schools: provide a superior-quality educational experience, nurture a professional and highly-skilled teaching staff to help students reach their full potential, and manage their schools in an efficient and cost-effective manner. As educational needs evolved, educational software, digital books and applications have increased in availability. Also, as technology advances with the proliferation of Internet connected mobile devices, such as smartphones and tablets, users are finding new methods to share information (Jain and Debra, 2007). As a result, educators are exploring ways to use these tools in the classroom to enhance learning and productivity. Most modern classrooms are expected to be connected to the Internet through WiFi or wireless broadband and are equipped with desktop PCs, notebooks and even tablet PCs. Classrooms are evolving from isolated learning environments into global collaborative learning centers. Internet access in schools, along with digital content development and learning management systems, has fostered real-time communication between students and teachers. One such kind of modern school is that developed through the Smart School program (Fiske, 1992). In developing countries, Smart Schools offer students an

\footnotetext{
${ }^{*}$ Corresponding author: Sirous Tabrizi

${ }^{\dagger}$ Email: sirous.tabrizi@gmail.com
} 
opportunity to learn beyond what is available in the other schools (Ming et al., 2010). Two developing countries in particular are involved in creating Smart Schools: Malaysia and Iran. In this paper, Smart Schools in these two countries will be examined and compared, to understand what opportunities and barriers still exist for improving the value and access of these schools. The Smart School program will be examined for both the state-sponsored public sector (state schools) and privately funded sector (private schools).

\section{LITERATURE REVIEW}

A direct correlation exists between demand for digital education tools and developers or suppliers of these tools, which means that insisting on having these instruments creates different opportunities in the academic field to gain new forms of access to information (Samsung, 2013). Governments are starting to understand the need for addressing the requirements of tech-savvy students. As a consequence, the majority of governments are starting to digitize public-school materials. Their initial target is to improve class management through interactive teaching tools. Although nearly all educators are informed of these changes, some of them are unsure about how the classroom teaching strategies will change. However, advanced schools prefer to use flexible and powerful electronic classroom tools, and are interested in finding new models for class management and learning engagement.

\section{Curriculum}

Baylor and Donn (2002) claimed that in the educational system, teachers' aims for Information and Communication Technologies (ICT) integration are created by seven fundamental factors: curriculum alignment, leadership, planning, professional development, teachers' openness to change, teachers' non-school computer use, and technology use. Integrating technology into the curriculum is a characteristic of a successful Smart School. This achievement is guided by a comprehensive technology-use plan, which explains the whole philosophy of technology use as well as prospects for how technology is able to improve learning and teaching. School leaders in this system should value and use ICT, and improve technology in the educational system through incentives and acknowledgements to reinforce its importance. Thus, leaders will be able to develop their strategies for establishing expectation of ICT use and effects. Teachers in all levels of education need adequate support, otherwise they become uncertain of successful practices, unable to participate with new strategies, and cannot correctly lead students through the technological system. External professional development is able to create new approaches and a positive atmosphere to observe new teaching and learning methods, and it persuades teachers to share their opinions and identify problems or difficulties (Baylor and Donn, 2002). This curriculum is designed to help students to achieve new skills, knowledge, value, and correct use of language. Learning outcomes are predesignated for diverse abilities, thus all students can access a similar quality of learning.

\section{Pedagogy}

The active learning process in Smart School pedagogy creates specific learning targets, where learners are able to learn continuously. Smart School pedagogy seeks to create learning strategies that increase students' motivation and interest, as well as involve the students' minds, spirits, and bodies in the learning process so as to prepare them for the highest challenges and a range of requirements. The pedagogy shall: "use an appropriate mix of learning strategies to ensure mastery of basic competencies and promote holistic development, accommodate individual different learning styles, so as to boost per- 
formance, and foster a classroom atmosphere that is compatible with different teachinglearning strategies" (Government of Malaysia, 1997, 11). The Smart School approach is consistent with diverse teaching-learning strategies; based on students' skills, knowledge, and abilities, teachers are interested in finding the best or most appropriate methods to teach them (Grana and Carlos, 2012).

\section{Assessment}

Assessment is a fundamental issue for any Smart School, and it has several characteristics that attempt to evaluate students in a holistic manner: achievement, progress, aptitude, and readiness (Government of Malaysia, 1997). The achievement characteristic assesses each intended learning outcome. For instance, has a student been able to achieve enough skills and knowledge in this level such that (s)he is ready to move on to the next level? The progress characteristic recognizes that students have different talents and attitudes. Therefore, it is necessary to monitor them to see that they were able to achieve the learning objectives' need. In doing so, the strengths and weaknesses of each student can be illustrated. The readiness characteristic evaluates the learners' experiences to determine if they have achieved a level of entry in certain learning area. Lastly, the aptitude characteristic helps to determine different styles of learning and intelligence of students, so that their achievements can be properly contextualized. Such a comprehensive form of evaluation is necessary. Since assessment is an important part of the teaching and learning process, and must be firmly established within the teaching process itself, systematic and logical methods are needed to increase learners' motivation towards learning and to develop sustainable learning.

\section{Teaching-Learning Materials}

Since the world is moving towards a global society, the Smart School program supports newer and higher quality materials which can increase students' flexibility in learning and be matched with students' individual learning skills and needs. Teaching-learning materials must support the curricular and instructional needs. Additionally, these materials are economical, as well as cosmetically and technically adequate in various ways-e.g., cost effectiveness, curriculum adequacy, technical adequacy, graphic and video quality, and instruction adequacy (Lumumba-Kasongo, 2000). In Smart Schools, technology gives instructors an opportunity to assess and consider learners' talents individually, and monitor their performance so their achievements are consistent with their actual abilities. The contents of these materials are based within a global approach, since this is the broader context into which students will eventually be living and working. It is also within this global context that the material will be designed such that it is cognitively challenging, attractive, motivating for students, and encourages active participation (Lumumba-Kasongo, 2000).

\section{mart School Management System (SSMS)}

The Smart School Management System (SSMS) determines and verifies the diverse objectives of the Smart School program within a particular context (e.g., a country). It does so by examining the country's strengths, weaknesses, opportunities, and threats. However, the primary objective of SSMS is to effectively and efficiently manage the resources and processes required to protect the teaching-learning functions. For example, SSMS in Malaysia has nine primary functions: facilities, financial management, educational resources, external resources, human resources, technology, security, school governance, and student affairs (Zajda and Donna, 2009). The functioning of Smart Schools is different from nor- 
mal schools. For example, authority in school governance is delegated between staff and stakeholders, so that relevant data can be gathered and used to ensure the school is suitable to the local learning and teaching environment. School governance also involves constructive communication, and consideration of school policy, curriculum, community, and management. Student affairs include student profiles, evaluations, performance, counseling, health, test administration, health, insurance, and so on. The purpose of including such affairs in the SSMS is to create effective and efficient management, engage stakeholders in management, respond to problems, and take appropriate strategies. Additionally, student affairs involve developing a comprehensive Student Record System (SRS) for the storage, retrieval, and reporting data that are related to students. This allows their parents and other stakeholders to monitor such information as needed. Furthermore, all students and teachers will be able to access the comprehensive resource database. Since some of the stored data is audio and video, this will decrease the educational costs (such as cost of managing resource information). External resources that would be useful for teachinglearning and management are also indexed in this database.

\section{Smart School Visions (Goals and Objectives)}

The Smart School program has, as their agenda, the accomplishment of five key goals: democratize education, increase learners' abilities and strengths, enhance participation of stakeholders, produce a considerate and technologically literate labor force, and develop the intellectual, emotional, spiritual, and physical skills of students (Musa, 2003).

For the first goal, democratizing education, two strategies are necessary. The first strategy is to provide equal access to learning, through equal opportunities within the curriculum. The second strategy is to incorporate different abilities, paces of learning, and learning styles within the curriculum. In doing so, all students have an equal opportunity to access high-quality learning and are able to learn at their own pace irrespective of grade. Since the second strategy is mediated by the teacher, it is necessary for teachers to ensure that such diversity exists in their available material.

The second goal is to provide opportunities to enhance individual strengths and abilities. The strategies related to this goal include a personalizable and customizable curriculum and allowing for vertical integration (Government of Malaysia, 1997). Vertical integration, in a business sense, is a strategy used by a firm to gain more control over its suppliers so as to reduce transaction costs, increase the firm's power in the marketplace, and secure supplies or distribution channels (Hill and Gareth, 2008). In Smart Schools, vertical integration means that students are not placed within a particular grade level but rather that there are grade levels for each subject within the school's curriculum. Hence, it is possible for a student to be simultaneously within multiple different grades, depending on his or her strengths and abilities. Curricula designed in this fashion allow students to remain connected with their peers without the peers impeding progress through school.

The third goal is to increase the participation of stakeholders in the school and education process itself. One strategy to achieve this goal is to create awareness of what the stakeholders would like to see in their school (Sailor, 2009). In taking a systems approach, stakeholders (e.g., in the school, community, state, Ministry of Education, and industry) play a fundamental role by being inputs to the system. To improve their responsibilities, their functions need to be designed and they need to receive appropriate and timely feedback, so that stakeholders within a successful Smart School can know how well the system is working. A second strategy is to provide quick and easy communication with the school using technology. For example, teachers, parents, and students can create constructive communication by e-mail when unable to meet together face-to-face. Additionally, parents 
and teachers can review the student progress record from the school website/database, and can become informed of student achievement in class. A third strategy is to enable opportunities for stakeholders to participate. Stakeholders will provide their opinion and suggestions for achieving the primary goals of the Smart School. For example, they can participate in a "parent support group meeting" every month to monitor the school's and students' progress (Government of Malaysia, 1997).

The fourth goal is to produce a thinking and technologically-literate workforce. A strategy to accomplish this goal is to include technology in teaching-learning, such as the Internet, as a teaching-learning material. Through this technology, students with different learning styles have equal opportunities to learn and are able to develop critical thinking skills within any subject of the curriculum (Chadyiwa, 2015; Idris, 2005; Tarmuchi, 2015).

Lastly, the fifth goal is to provide all-round development of the individual such as intellectual, emotional, spiritual, and physical growth (Kirana, 2003). Intellectual qualities can be improved through learning how to search, collect, analyze, and use knowledge with an emphasis on creativity and problem-solving. Emotional and spiritual qualities are a subset of topics in the Smart School meant to instil moral and religious adaptability, team-player characteristics, emotional intelligence, and emotional balance. Finally, the physical quality refers to improving health, their environment, and creating a conscious awareness of both aspects (Government of Malaysia, 1997).

\section{Smart School Visions (Stakeholders)}

There are five categories of stakeholders that play an important role in monitoring the state of a Smart School: school, community, Ministry of Education, governmental, and industry stakeholders (Bajunid, 2008). In this section, only three groups will be discussed: teachers, parents, and students. These three are the most important in terms of achieving the goals of Smart School (Multimedia Development Corporation, 2005). Parents are a kind of community stakeholders, while teachers and students are school stakeholders. However, all three of these groups work together and are a major factor in carrying out the goals and objectives.

Teachers are the main driving force in this case, given their role in transferring data to students and assessing students. In order to play their role effectively in accomplishing the goals of a Smart School, they must have planned and prepared learning activities for the students to enjoy in their assigned learning time, either inside the classroom or outside of it (Nash, 2013). For example, teachers could do an Internet search on the topic that will be discussed in the next session of their lesson. Next, they should provide additional material that is related to the topic so that students have more reference material than just their textbooks and workbooks. Furthermore, teachers have to be ready in using visual, auditory and kinaesthetic learning in order to make the learning more efficient. They also enrich Smart Schools with their knowledge. Highly motivated teachers want to understand and use new technology, so that they can introduce it to students in a way that students can use to do research instead in simply passing their examinations. Students' growth depends on the teachers' ability to optimise the usage of ICT facilities. Teachers must deliver different kinds of data to parents and students; this requires various computational tools involving email, multimedia, and the Internet. Another important role for teachers is classroom management. This can give a good opportunity for students to learn various material and develop self-motivation, self-control, and self-assessment. Additionally, good communication between teachers and students will lead to higher efficiency and effectiveness of classroom management; this is especially so if teachers can create a clear and logical program to enhance students' knowledge (Government of Malaysia, 1997). Students 
are the second of the school stakeholders that are a pivotal group in the Smart School. Students facilitate the accomplishment of Smart School goals, and students who are self-paced learners are more able to accomplish these goals (Government of Malaysia, 1997). They learn to use many initiatives with teamwork, which can help them to learn much better in school as well as outside of it. In this system, students can be more proactive, energetic, and self-motivated (Grana and Carlos, 2012). As such, learning policies need to be established on a student-centered model, otherwise learning may not be sufficiently effective. Critical thinking is an active method applied by students, because it enables students to reflect on what they have learned as well as the quality of this knowledge (Grana and Carlos, 2012).

Parents is the last group of the stakeholders that will be looked at, and they are an example of community stakeholders. Parents play a significant role in all school systems; they are able to improve their children's motivation and counsel them to recognise their weaknesses and strengths (Spock, 2012). Parents are able to monitor students in school, given the way that Smart Schools give feedback to parents, as well as away from school when students are at home. However, parents can create an inequality between students through various economic, educational, and behavioral factors (Teese et al., 2007). Parents collaborate in various school programs such as by: giving donations, receiving information from school plans, and giving suggestions to create a better atmosphere in the school. Additionally, close and logical relationships between parents and teachers are necessary so that proper communication can occur. Through parents sharing information about their children's interests, weaknesses, and strengths teachers have more information to create better and more practical teaching plans (Strip and Gretchen, 2000).

\section{Study}

In Malaysia, the Smart School program was started in early 1996. Information about the state of this program in Malaysia can be seen in the literature review above. After the Iranian president (Mr. Khatami) visited Malaysia, the Smart School program was also started in Iran. This was around 2002. Although the Iranian governors restricted Internet usage, a fundamental tool necessary for the Smart School program, a more thorough study of the state of Iranian Smart Schools has not been conducted. The purpose of this study then is to explore what the current constraints, weaknesses, and problems are with the Smart Schools program in Iran. In other words, this study fundamentally seeks to understand to what extent the Iranian school system is ready to establish the Smart Schools program.

\section{METHODOLOGY}

This study is a qualitative one. Qualitative research aims to collect in-depth understanding of human actions. Such research looks at the how and why of human action and not simply the where, what, and/or when (Mariampolski, 2001).

\section{Data collection}

In this research data were gathered by formal and informal interviews. The interviews were conducted in Turkish and Persian, and then transcribed and translated to English. Even though interviewing is a popular method for collecting data, the accuracy and truthfulness of these data are fundamental for its usefulness. Nearly all of the questions are open-ended, with some close-ended questions to create a more reliable interview environment. Two people were interviewed: an Information Technology Expert (ITE) who works in state schools and a Smart School Administrator (SSA) from Tehran (capital of 


\section{Target}

This study was conducted in the Northwest province of Iran. The interviewee chosen from the state school is a professional in Information Technology (IT) and has graduated from university with a Master's degree. This individual was chosen to recognize and assess how well the Smart School program has been implemented in state schools of Iran.

\section{RESULTS}

After the interviews were conducted, it became obvious that a comparison between Smart Schools in Malaysia and Iran was problematic. This was due to significant differences between how the Smart School program was implemented in Iranian private and state schools. Therefore, this section will briefly include comments from the ITE about Smart Schools in state schools. Comments from SSA will be included in the Discussion section below, where a comparison between the Smart School program in private schools in Iran and schools in Malaysia can be made. ITE explained that:

"If we divide schools into three groups-such as primary, secondary, and high schoolsalmost all teachers in primary and secondary schools are not trained in research methods. Thus, they are not able to transfer this approach to learners. Teachers in high schools have various situations. Those who teach computer courses have to keep up-to-date about technology while teachers in other courses such as mathematics, chemistry, languages (Persian, Arabic, and English), history, and so on do not need to study new topics or learn how to use the Internet."

Teachers in the state schools simply used traditional methods of schooling, and "nearly all of teachers are not familiar with the Smart School". Although the teachers who teach computer courses have to learn new software and pass some accreditation courses, "not many of them are motivated or knowledgeable". ITE further explained that "in my opinion, teachers are not ready to work in the Smart School program. They have to update their knowledge, skills, and other capacities such as teamwork and brainstorming. They should even review their approach to class management." When asked about the state of the material, ITE said: "nearly all of the material is theoretical. Students learn to memorize all phenomena. However, students need practical courses or materials that are related to Smart Schools which lead students to the laboratory to do research. In doing so, long-term learning will emerge. Hence, students need to learn methods of research." When asked to explain any existing courses that relate to the Smart School program, ITE mentioned one:

"In this province, all state schools just have one class which is called 'smart class'. Some new instruments which utilize ideas from the Smart School program are combined and included in it. Teachers can reserve this class, and take some time to teach his/her courses using these instruments. However, this can be done only once or twice per year. Teachers and students cannot connect to the Internet in state schools. Sometimes it is possible to connect to 'Meli Site', which means that they can get information from the 'Roushd' site but that is all".

When asked about the state of community stakeholders, he explained that they have very limited involvement: "Many of students who are in state schools are from families in a low socio-economic state. Therefore, this type of stakeholder cannot contribute. Cooperation and consultation between schools and families are at the very minimum level. Generally speaking, many of the families are illiterate or have a low education."

\section{DISCUSSION}

From the results, it should be clear that state schools in Iran are not ready to implement the vision and strategies of the Smart School program. In this section then, a discussion will 
be conducted comparing the state of Smart Schools in the Iranian private schools (from the SSA's comments) and in Malaysian schools.

\section{Curriculum}

The Smart School curriculum is based on best practices and elements that help it to achieve its goals. The SSA explained that, "Malaysia has a predefined program that educates children with critical thinking combined with values that encourage and promote: proficiency with language, developing at their own pace, holistic learning, and the capabilities and interests of each student. Iran has the same program. However, the Malaysian Smart School Curriculum Vision focuses on particular subjects which differ from Iran. The Iranian vision does not contain some of those of Malaysia, such as multiculturalism, social responsibility, self-reflection, global outlook and foundation, and technological approach."

\section{Pedagogy}

The Smart School pedagogy is student-centred, which is intended to lead to learning that is more interesting, stimulating, motivating, and meaningful. In the Malaysian Smart School, the learning process involves the body, mind, and spirit of students (Government of Malaysia, 1997). Students learn skills that help them overcome future challenges. These Smart Schools utilize some innovative methods of teaching that focus on: Process (i.e., involves specific learning objectives), Modes (i.e., education could be alone, in small groups, or in pairs; includes teachers, facilities, and non-human resources), and Tasks (i.e., real world challenges; real life environments with some general skills and specific knowledge) (Government of Malaysia, 1997). In comparison, the SSA said that:

"Although Iran and Malaysia are Islamic countries, and some educational factors regarding a human being and his spiritual issues are the same, education in Iran is more theoretical. Additionally, in Iran, almost all of the families who send their children to a Smart School expect that it will allow their children to pass the comprehensive exams and thus enter university. Any individual talent of a student is not important, unless it helps them pass this exam."

\section{Assessment}

One of the major factors that distinguishes the Smart School from traditional schools is the assessment system. This system is designed with certain goals in mind, such as including guidance from the National Philosophy of Education, being flexible and learnerfriendly, assuring quality, and providing a more precise image of a student's achievement, readiness, aptitude, learning styles and abilities (Government of Malaysia, 1997). The SSA mentioned that:

'If an accurate assessment reveals logical data about learners' capacity, sometimes we are not able to use this result in decision making. This is because Iranian Smart Schools have some constraints, such as governmental regulation, families' cultural expectations, teachers' experience, and students' readiness." Furthermore, the SSA added that "in Smart Schools we need to change the architecture of the building, but financial problems limit us." When he was asked about the architectural needs, he replied:

"For example, in our school students must work as a team. This means four students are in a team and they work with a computer on a table. Thus, our classroom structure needs to accommodate this, but it uses a traditional model. As well, since we teach courses using some electronic instruments, the number of students in our classes are less than state or other private schools but need to be carefully regulated. If four students are in a team, and a new student comes in, we need three more students so that this new student can work 
in a proper team. Furthermore, the students' talents and capacities are different than the cost per person as indicated by the Ministry of Education. Hence, we do not get the proper support from them. Students' registration depends on the school's capacity. They have to take an exam, but this is different from other private schools. We designed several exams to assess not simply entry qualifications but diverse talents as well. [...] I know in Malaysia students have more educational opportunities in the Smart School."

\section{Teaching-Learning Materials}

In Smart Schools, a different style of teaching-learning materials is needed. These materials are designed to wholly support the new teaching-learning strategies. In this area, the Ministry of Education in Malaysia considers the curriculum and instructional needs, cost effectiveness, and technical adequacy (Government of Malaysia, 1997). Additionally this material is then adjusted to be cognitively attractive, challenging, able to motivate students to learn, and encourages active participation. Finally, it is then implemented to incorporate the best style of courseware material that is specific to the teacher and network (Government of Malaysia, 1997). While in Iran, the material is different. As the SSA explains:

'I am not satisfied with our students' learning. Most of the families do not have a close relationship with our school, nor do they contribute to it. Our school's strategies and the aspirations of the parent are not moving in the same direction. Additionally, financial problems and governmental regulations are fundamental problems that restrict the possibilities for teaching the necessary material."

\section{Smart School Management System (SSMS)}

The main goal of Smart School management is to manage all resources efficiently and effectively. Although the organizational charts of the Ministry of Education in Iran and Malaysia are top-down, Malaysia was successful in defining correct responsibilities for school management while school managers in Iran have to monitor all aspects of the school. For example, a typical day in the life of a smart school principal in Malaysia that highlights some of his duties is shown in Table 1.

TABLE 1. Some responsibilities in a typical day for a smart school principal (adapted from Government of Malaysia, 1997)

\begin{tabular}{ll}
\hline \hline Time & Responsibility \\
\hline 8:30 am & Participate in a video conference meeting of secondary school principals in the district to discuss discipline issues. \\
10:30 am & Send e-mail to staff and parents to inform them of latest developments in regulations regarding student discipline. \\
$1: 00 \mathrm{pm}$ & Access a student's progress records from the school database in preparation for a meeting with his parents regardi- \\
& ng his underachievement in class. \\
$2: 00 \mathrm{pm}$ & Attend staff meeting to discuss the up-coming school Sports Day and to delegate duties. \\
4:00 pm & Respond to e-mail \\
$5: 00 \mathrm{pm}$ & Visit "Principals' Corner", a discussion group on the Internet \\
\hline \hline
\end{tabular}

As can be seen in Table 1, a Malaysian principal's main responsibilities are managing data (Government of Malaysia, 1997). In Iran, all duties are under the control and jurisdiction of the principal (Tabrizi, 2013). This includes overseeing: security, meetings, accountability, planning, organizing, staffing, budgeting, coordinating, and reporting to three other management levels. Thus, these principals do not have enough time to do any one primary or essential responsibility. As the SSA explained, "most of the time I have to be in meetings and manage the budget."

\section{Smart School Vision}

The SSA explained that the Smart School vision in Iran "is related to the policies of the Ministry of Education and the requests of families. Even though we try to develop a global 
approach, we have to follow the curriculum of the Ministry and our students are encouraged to only look at entering university". He further stated,

"I would like to divide the Smart School Vision in two parts: Software and hardware. In hardware we are in a good position; by this I mean our classes, computers, and other instruments are provided for the Smart School but we have a problem with the Internet and limitations in accessing it. Our fundamental obstacles are related to software: teaching materials, teachers who are not self-motivated-I know many of them have financial problems-, students who do not know their real objectives, an assessment system that is subjugated by the university entrance exams, and finally families' requests. Malaysia has been successful in following the Smart School's vision such as democratizing education, increasing learners' abilities and strengths, enhancing participation of stakeholders, producing a considerate and technologically literate labor force, and developing the individual's intellectual, emotional, spiritual, and physical skills."

\section{Stakeholders}

The SSA said that the most active stakeholders are the School's staff, teachers, parents, and students. These stakeholders have one common issue: "the student must be successful in the comprehensive exam to enter universities". The SSA added, "many of my students are from rich families. Even though a majority of the parents are highly educated, they do not have a close relationship with our school. If I try to use various methods, like brainstorming, to get new ideas, their ability to work with us is very poor." In terms of the parent's role, the SSA elaborated it: "Parents get a report about the students' educational situation monthly, and in a critical situation they will receive a special notice." When asked about the other stakeholders, the SSA said: "Teachers have a higher motivation in spite of their financial problem, but I don't think students are active enough. I believe they should be challenged more. We arrange reinforcement classes for students who are poor in some subjects, but these classes are not enough for them."

\section{REFERENCES}

Bajunid, Ibrahim A. 2008. The development of educational leaders in Malaysia: The creation of a professional community. In Teaching: Professionalization, development and leadership. Amsterdam, ND: Springer.

Baylor, Amy L., and Donn Ritchie. 2002. What factors facilitate teacher skill, teacher morale, and perceived student learning in technology-using classrooms? Computers and Education vol. 39, no. 4: 395-414.

Chadyiwa, Martha, and Mgutshini T. 2015. Using mobile handheld devices as tools of learning and teaching for Student EHPS: A blessing or a curse? International Journal of Humanities, Arts and Social Sciences 1, no. 2: 85-91.

DOI: 10.20469/ijhss.20005-2

Elias, Maurice J. 1997. Promoting social and emotional learning: Guidelines for educators. Alexandria, VA: Association for Supervision and Curriculum Development.

Fiske, Edward. 1992. Smart schools, smart kids: Why do some schools work? New York, NY: Simon and Schuster. Government of Malaysia. 1997. Smart school conceptual Blueprint. URL: https://goo.gl/srSVGP (accessed December 14, 2016).

Graña, Manuel, and Carlos Toro. Eds. 2012. Advances in knowledge-based and intelligent information and engineer- ing systems. Amsterdam, ND: IOS, Press, Inc.

Hill, Charles WL., and Gareth R. Jones. 2008. Strategic management: An integrated approach: An integrated approach. Stanfard, CT: Cengage Learning.

Idris, Noraini. 2005. Teaching and learning of mathematics. Kuala Lampur, MY: Utusan Publications. ISSN: 2414-3111 
Jain, Lakhmi C., and Debra K. Tedman. 2007. Evolution of teaching and learning paradigms in intelligent environment. Vol. 62. Queensland, AU: Springer.

Kirana, Pavana C. 2003. Sikkim, perspectives and vision: Speeches of Chief Minister Pawan Kumar Chamling. New Delhi, IN: Govt. of Sikkim in Association with Indus Publication Co.

Lumumba-Kasongo, Tukumbi. Ed. 2000. Dynamics and policy implications of the global reforms at the end of the second Millennium. Vol. 78. Boston, MA: Brill.

Mariampolski, Hy. 2001. Qualitative market research: A comprehensive guide. Thousand Oaks, CA: Sage Publications.

Ming, Thang S., Carol Hall, Hazita Azman, and Gordon Joyes. 2010. Supporting smart school teachers' continuing profes- sional development in and through ICT: A model for change. International Journal of Education and Development using Information and Communication Technology; Bridgetown 6, no. 2: 5-20.

Multimedia Development Corporation. 2005. The Smart School Roadmap 2005-2020: An educational odyssey. URL: goo.gl/quzjHq (accessed December 14, 2016).

Musa, Bakri M. 2003. An education system worthy of Malaysia. New York, NY: Writers Club Press.

Nash, Ron. 2013. The active classroom: Practical strategies for involving students in the learning process. New York, NY: Corwin Press.

Sailor, Wayne. 2009. Making RTI work: How smartschools are reforming education through school wide response-to- $\quad$ intervention. San Francisco, CA: John Wiley \& Sons.

Samsung. 2013. Samsung smart school, An interactive and collaborative learning environment for the next-generation classroom. URL: https://goo.gl/qUzjHq (accessed December 14, 2016).

Spock, Benjamin. 2012. Dr. Spock's Baby and child care: Time-tested parenting advice fully updated for 2012. New York, NY: Skyhorse Publishing Inc.

Strip, Carol Ann, and Gretchen Hirsch. 2000. Helping gifted children soar: A practical guide for parents and teachers. Scottsdales, AZ: Great Potential Press, Inc.

Tabrizi, Sirous. 2013. Investigating high attrition rate of boys in Iranian schools. Saarbrücken, Germany, DE: Lambert Academic Publishing.

Tarmuchi, Nor Rashimahwati, Haslinda Mohamed, and Saidatul Akmar I. 2015. Asynchronous learning tools use in graduate study: A preliminary survey. International Journal of Humanities, Arts and Social Sciences 1, no. 1: 13-18.

DOI: 10.20469 /ijhss.20003

Teese, Richard, Stephen Lamb, Marie Duru-Bellat, and Sue Helme. Eds. 2007. International studies in educational in- $\quad$ equality, theory and policy. Vol. 1. Dordrecht, Netherlands: Springer.

Zajda, Joseph, and Donna Gibbs. 2009. Comparative information technology: Languages, societies and the Internet. Amsterdam, Netherlands: Springer

— This article does not have any appendix. — 